\title{
Thermal, mechanical and morphological properties of polypropylene/clay/wood flour nanocomposites
}

\author{
S. Y. Lee ${ }^{*}$, I. A. Kang1, G. H. Doh', W. J. Kim¹, J. S. Kim², H. G. Yoon ${ }^{2}$, Q. Wu \\ ${ }^{1}$ Division of Environmental Material Engineering, Department of Forest Products, Korea Forest Research Institute(KFRI), \\ Hoegi-Ro 57, Dongdaemun-Gu, Seoul, 130-712, Korea \\ ${ }_{2}^{2}$ Department of Material Science and Engineering, Korea University, Anam-5Dong, Seongbuk-Gu, Seoul, 136-713, Korea \\ ${ }^{3}$ School of Renewable Natural Resources, Louisiana State University Agricultural Center, Baton Rouge, LA 70803, USA
}

Received 1 September 2007; accepted in revised form 11 December 2007

\begin{abstract}
Nanocomposites with polypropylene/clay/wood flour were prepared by melt compounding. Thermal, mechanical and morphological properties were characterized. The addition of clay, compatibilizer and wood flour considerably improved the thermal stability (i.e., decomposition and melting temperatures) of the hybrids. The tensile modulus and strength of most hybrids were highly increased with the increased loading of clay, MAPP and wood flour, compared to the hybrids without wood flour. The wide angle X-ray diffraction (WAXD) patterns showed the increased d-spacing of clay layers, indicating enhanced compatibility between PP and clay with the addition of maleated polypropylene (MAPP). The transmission electron microscopy (TEM) photomicrographs illustrated the intercalated and partially exfoliated structures of the hybrids with clay, MAPP and wood flour.
\end{abstract}

Keywords: nanocomposites, nanoclay, MAPP, PP, wood

\section{Introduction}

Composites can be tailored to have the desired properties by incorporating particulate fillers into a polymer matrix to suit different applications. There has been an increasing use of composites in myriad fields from the residential buildings to aeronautics industries [1]. Lignocellulosic fillers such as wood flour, rice husk, jute and sisal have numerous advantages over glass fibers including low cost, biodegradability, easiness of processing and the absence of toxic byproducts. Therefore, they have been widely used as reinforcements for thermoplastic composites [2-5]. The addition of wood flour to neat thermoplastics can greatly stiffen them, but makes them more brittle at the same time $[2,6,7]$. Compatibilizers such as maleated polyethylene (MAPE) and maleated polypropylene (MAPP) played an important role in improving the compatibility and bonding strength between hydrophilic wood flour and hydrophobic thermoplastics [8-10]. Composites with structure and composition at the nanoscale exhibit highly improved mechanical properties and high temperature endurance [11-14]. Among the inorganic layered materials, layered silicates are often used for inclusion in the hybrids due to their ability to intercalate and exfoliate at the nanoscale in the thermoplastic matrix. In particular, the smectite group of clay minerals like montmorillonite (MMT) has been predominantly used, due to its excellent intercalation ability [15-20].

Since thermoplastics such as polyethylene (PE) and polypropylene (PP) are hydrophobic and have poor miscibility with hydrophilic layered silicates, nan-

*Corresponding author, e-mail: nararawood@ forest.go.kr

(C) BME-PT and GTE 
oclay was usually organo-chemically modified with alkylammonium groups to facilitate their interaction with thermoplastics. In addition, the miscibility between nanoclay and PE or PP can be improved by the addition of compatibilizers such as MAPE, MAPP or carboxylated PE [18, 21].

There are two concepts of intercalation and exfoliation, which can define the structures in clay-polymer hybrids. Intercalation, defined as the wellordered and stacked multilayers that result from intercalated polymer chains within host nanoclay layers. Exfoliation refers to formation of monolayers of clay well-dispersed in a continuous polymer matrix or individually distributed in the polymer matrix. The intercalated and exfoliated hybrids exhibit improved in strength and modulus, compared with neat polymer and conventional composites [11-14,16-18].

The enhanced properties of the composites can be achieved at a low clay loading level (e.g., less than $5.0 \mathrm{wt} \%$ addition of clay) [22]. At the $5 \mathrm{wt} \%$ clay loading, an approximately $70 \%$ increase in modulus and strength was observed for Nylon-clay systems, and both heat distortion temperature and impact strength also increased by more than $100 \%$ [23]. However, the dispersion of clay layers in most polymers is not easily accomplished due to face-toface stacking in agglomerated tactoids and the conversion to a single platelet by complete exfoliation $[24,25]$.

Although some studies have been conducted on the reinforcement effect of clay in thermoplastics such as PP and PE, limited data is available on the wood flour/clay/plastic hybrids by melt compounding. With the presence of larger-size wood fibers, a synergetic combination of clay and coupling agent is often needed to achieve desired composite properties [21]. The objective of this study was to examine the effect of wood flour, clay, compatibilizer on thermal, mechanical and morphological properties of PP-based composites. Wide angle X-ray diffraction (WAXD), transmission electron microscopy (TEM), thermogravimetric analysis (TGA), differential scanning calorimetry (DSC) and stress-strain behavior were used to evaluate composite properties.

\section{Materials and methods}

\subsection{Materials}

Polypropylene (PP 5014, $M_{w}=180000 \mathrm{~g} / \mathrm{mol}$ ) was obtained from the Korea Petrochemical Ind. Co., Ulsan, South Korea. Neat PP was in the form of homopolymer pellets with a melt flow index of $3.2 \mathrm{~g} / 10 \mathrm{~min}$ and a density of $0.9 \mathrm{~g} / \mathrm{cm}^{3}$. The wood flour (Lignocel C120, particle size of 100120 mesh per $2.54 \mathrm{~cm}^{2}$ ) was supplied from J. Retenmaier \& Sohne Co. (Rosenberg, Germany) and manufactured from some European softwood. Maleated polypropylene (MAPP; PH-200, Honam Petrochemical Co., Daejeon, Korea) was used as a compatibilizer. The molecular weight and maleic anhydride grafting level of MAPP were $40000 \mathrm{~g} / \mathrm{mol}$ and $5 \%$, respectively. Clay (Montmorillonite, Cloisite ${ }^{\circledR} 15 \mathrm{~A}$ ), chemically-modified with a quaternary ammonium salt was purchased from Southern Clay Products, Inc. (Gonzales, Texas, U.S.A.). The clay was a fine powder with a cation exchange capacity of 125 mequiv/100 g. The density and layer distance of clay were $1.6 \mathrm{~g} / \mathrm{cm}^{3}$ and $30.3 \AA$, respectively. The clay was dried in a vacuum oven at $90^{\circ} \mathrm{C}$ for $24 \mathrm{~h}$ prior to use. The wood flour was dried to $1-2 \%$ moisture content using an oven at a temperature of $80^{\circ} \mathrm{C}$, and then stored in polyethylene bags until needed.

\subsection{Melt compounding}

The hybrids with wood flour/clay/PP were prepared with a co-rotating twin-screw extruder (Bautek Co, Uijungbu-city, Korea). The extruder had a screw diameter of $19 \mathrm{~mm}$ with an $L / D$ ratio of 40 . A compounding temperature of $190^{\circ} \mathrm{C}$ was used to prevent the thermal degradation of the wood flour. The screw speed for compounding was in the range of 100-150 rpm, depending on the processing speed through a circular nozzle. The loading levels were $0,10,20$ and $30 \mathrm{phr}$ (part based on one hundred resin) for wood flour, 0, 1, 3 and $5 \mathrm{phr}$ for clay, and 3, 6 and $10 \mathrm{phr}$ for MAPP. The neat $\mathrm{PP}$ (used as control), PP/clay and PP/clay/MAPP hybrids were compounded using a one-step method. A two-step method was used to compound wood flour with PP/clay/MAPP hybrids. In the two step process, PP/clay/MAPP hybrids were compounded and palletized first, and then wood flour was finally compounded with the pellets of PP/clay/MAPP 
hybrids. The extrudate in the strand form was aircooled and pelletized with a pelletizer (Bautek Co., Uijungbu-city, Korea). The hybrid samples were dried at $90^{\circ} \mathrm{C}$ for $24 \mathrm{~h}$ in a vacuum oven to remove the absorbed water before being injection molded at $190^{\circ} \mathrm{C}$ and then cooled to room temperature.

\subsection{TGA and DSC}

Thermogravimetric analysis (TGA) was used to investigate thermal decomposition behavior of hybrids with a SDT Q600 Thermogravimetric analyzer (TA Instrument Inc. New Castle, Deleware, U.S.A.). Tests were done under nitrogen at a scan rate of $10^{\circ} \mathrm{C} / \mathrm{min}$ in a programmed temperature range of 30 to $600^{\circ} \mathrm{C}$. A sample of 5 to $10 \mathrm{mg}$ was used for each run. The weight change was recorded as a function of temperature. Derivative peak temperature $\left(D T_{p}\right)$ was taken as the maximum temperature acquired from the differentiation of the weight change as a function of time. Differential scanning calorimetry (DSC) experiments were performed with a DSC Q10 system (TA Instrument Inc. New Castle, Deleware, U.S.A.). Each sample was heated and cooled at a scanning rate of $10^{\circ} \mathrm{C} / \mathrm{min}$ under nitrogen atmosphere in order to prevent oxidation. A test sample of 5 to $10 \mathrm{mg}$ was placed in an aluminum capsule and heated from 30 to $200^{\circ} \mathrm{C}$ for each run. The melting temperature $\left(T_{m}\right)$, enthalpy $\left(\Delta H_{m}\right)$, crystallization temperature $\left(T_{c}\right)$, crystalline enthalpy $\left(-\Delta H_{m}\right)$ and crystallinity $\left(X_{c}\right)$ were determined after the melt-crystallization process.

\subsection{Tensile properties}

The tensile strength test for hybrids was performed according to ASTM D638 using an Universal Testing Machine (Zwick Testing Machine Ltd., Leomister, United Kingdom). Test specimens were molded in a size of $3.18 \mathrm{~mm}$ (width), $63.66 \mathrm{~mm}$ (length) and $3.00 \mathrm{~mm}$ (thickness) with a gauge length of $12.5 \mathrm{~mm}$. Tensile strength and modulus were determined the testing machine with an extensometer at a crosshead speed of $10 \mathrm{~mm} / \mathrm{min}$. For each treatment level, five replicated specimens were tested.

\subsection{Wide angle $X$-ray diffraction (WAXD)}

The intercalation of the clay layers in the hybrids was investigated using a wide angle $\mathrm{X}$-ray diffrac- tometer (WAXD: Model Rigaku ATXG, Rigaku Corp., Tokyo, Japan). Measurements were performed using a nickel-filtered $\mathrm{Cu}-\mathrm{K}_{\alpha 1}$ radiation source under a voltage of $50 \mathrm{kV}$ and a current of $300 \mathrm{~mA}$. The WAXD scans were obtained in the reflection mode using an incident X-ray wavelength of $31.5 \AA$ at a scan rate of 0.01 degree $/ \mathrm{min}$ from a $2 \theta$ range of 2 to $10^{\circ}$. The interlayer distance of clay in the hybrids was calculated by Bragg's law $(d=n \lambda / 2 \sin \theta)$ from the (001) plane diffraction peak in the WAXD pattern with $d$ as the distance between the atomic layers in a crystal, $\lambda$ as the wavelength of the incident X-ray beam, and $n$ an integer.

\subsection{Transmission electron microscopy (TEM)}

The morphology of the hybrids was imaged using a Phillips CM 30 transmission microscope (TEM: FEI Company, Hillsboro, OR, U.S.A.) with an acceleration voltage of $200 \mathrm{kV}$. Ultra-thin sections of 70-90 nm were cut from injection molded bars perpendicular to the flow direction under cryogenic conditions using a Nova CM-20 ultramicrotome and then placed on 300 mesh grids.

\section{Results and discussion}

\subsection{Thermal properties}

\subsubsection{TGA results}

TGA curves of PP/clay hybrids are shown in Figure 1a. With the addition of clay ( 1 to $5 \mathrm{phr}$ ), a $67^{\circ} \mathrm{C}$ increase in decomposition temperature compared to neat PP was observed at the 50\% weight loss level. The increase in decomposition temperature is attributed to the hindered diffusion (i.e., barrier effect) of volatile decomposition products caused by the dispersed clay particles in the PP matrix [26]. The derivative peak temperature $\left(D T_{p}\right)$ of neat PP was $403.7^{\circ} \mathrm{C}$, while the hybrids with clay ( 1 to $5 \mathrm{phr}$ ) showed an increase in the derivative peak temperatures in the range of 17 to $32^{\circ} \mathrm{C}$. Figure $1 \mathrm{~b}$ shows the TGA thermographs of the hybrids with and without compatibilizer. The addition of compatibilizer ( $3 \mathrm{phr}$ ) to the hybrids increased the decomposition temperature by about $20^{\circ} \mathrm{C}$ compared to that of hybrids without compatibilizer. This increase was probably due to the physico-chemical adsorption of the volatile prod- 

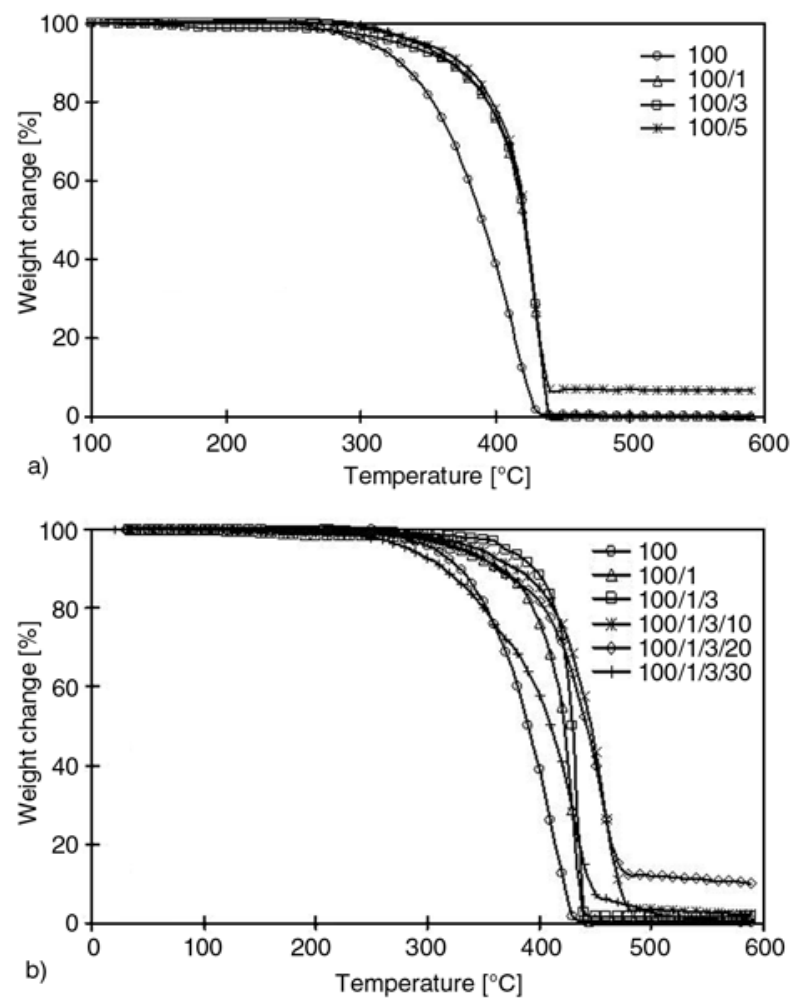

Figure 1. TGA thermographs of (a) PP/clay hybrids, and (b) PP/clay/MAPP/wood flour hybrids

ucts on the clay [27], which indicates that the dispersion of clay was improved by the addition of compatibilizer in polymer. The TGA thermographs of the hybrids with wood flour/clay/compatibilizer are shown in Figure 1b. The addition of wood flour (10 and $20 \mathrm{phr}$ ) increased the decomposition temperature of clay/compatibilizer hybrids. At the 50\% weight loss level, the addition of $10-20 \mathrm{phr}$ increased the decomposition by $40^{\circ} \mathrm{C}$, whereas the decomposition temperature decreased slightly at the level of $30 \mathrm{phr}$ wood flour.

\subsubsection{DSC results}

Table 1 shows the DSC results of PP/clay/wood flour/compatibilizer hybrids used in this study. All hybrid systems had a higher melting temperature $\left(T_{m}\right)$, compared to neat PP. Neat PP had the lowest $T_{m}\left(163.1^{\circ} \mathrm{C}\right)$, while hybrids with clay $(5 \mathrm{phr}) /$ MAPP (10 phr)/wood flour (20 phr) had the highest $T_{m}\left(166.1^{\circ} \mathrm{C}\right)$. The increased loading level of clay and MAPP had no significant effect on the $T_{m}$ of the hybrids. At $1 \mathrm{phr}$ loading of clay, the $T_{m}$ increased up to $2.1^{\circ} \mathrm{C}$ with increasing wood flour content (Figure 2a). However, at the 3 and $5 \mathrm{phr}$
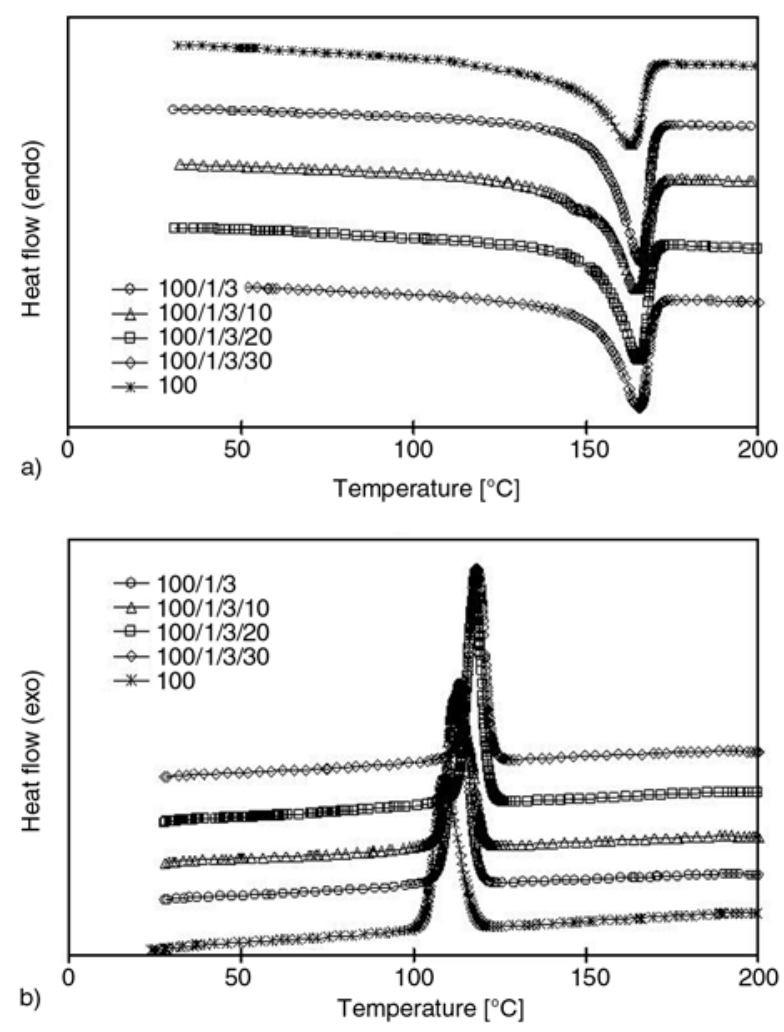

Figure 2. DSC melting results of PP/clay/MAPP/wood flour hybrids. (a) endo heat flow; (b) exo heat flow

clay loading level, the effect of wood flour on the change of $T_{m}$ was not significant (Table 1).

The enthalpy $\left(\Delta H_{m}\right)$ of caloric processes was determined at the heating rate of $10^{\circ} \mathrm{C} / \mathrm{min}$ (Table 1). The $\Delta H_{m}$ of neat PP at transition temperature was $81.8 \mathrm{~J} / \mathrm{g}$, but the $\Delta H_{m}$ with different clay (1 to $3 \mathrm{phr}$ ) and MAPP (3 to $10 \mathrm{phr}$ ) loading levels ranged from 87.5 to $90.4 \mathrm{~J} / \mathrm{g}$, indicating an increasing thermal stability. Meanwhile, the addition of wood flour from 10 to $30 \mathrm{phr}$ decreased the $\Delta H_{m}$ from 11.8 to $21.0 \mathrm{~J} / \mathrm{g}$. This result indicates that wood flour absorbed more heat energy in the melting of the composites as the $\Delta H_{m}$ of wood flour was much lower than that of neat PP [28].

The crystalline peak temperature $\left(T_{c}\right)$ of the hybrids is shown in Table 1 . The $T_{c}$ of $\mathrm{PP}$ was $108.7^{\circ} \mathrm{C}$, and the addition of clay ( $1 \mathrm{phr}$ ) and MAPP (3 phr) increased the $T_{c}$ to $111.9^{\circ} \mathrm{C}$. Clay and MAPP act as a nucleating agents, which increase the crystallization temperature of PP matrix [20, 29, 30]. The addition of wood flour (10 to $30 \mathrm{phr}$ ) to the hybrids increased the $T_{c}$ to $118.3^{\circ} \mathrm{C}$ (Figure $2 \mathrm{~b}$ ). The addition of wood flour $(30 \mathrm{phr})$ to PP/clay/MAPP hybrids increased the $T_{c}$ by up to $6.4-7.9^{\circ} \mathrm{C}$ com- 
Table 1. Thermal and tensile properties of PP/clay/MAPP/wood flour hybrids

\begin{tabular}{|c|c|c|c|c|c|c|c|c|}
\hline \multirow{2}{*}{ Systems } & \multirow{2}{*}{$\begin{array}{c}\text { PP/Clay/ } \\
\text { MAPP/WF }\end{array}$} & \multicolumn{5}{|c|}{ Thermal properties } & \multicolumn{2}{|c|}{ Tensile properties } \\
\hline & & $\begin{array}{c}\mathbf{T}_{\mathbf{m}} \\
{\left[{ }^{\circ} \mathbf{C}\right]}\end{array}$ & $\begin{array}{l}\Delta \mathbf{H}_{\mathbf{m}} \\
{[\mathbf{J} / \mathbf{g}]}\end{array}$ & $\begin{array}{c}\mathbf{T}_{\mathbf{c}} \\
{\left[{ }^{\circ} \mathbf{C}\right]}\end{array}$ & $\begin{array}{c}-\Delta \mathbf{H}_{\mathbf{m}} \\
{[\mathrm{J} / \mathrm{g}]}\end{array}$ & $\begin{array}{c}\mathbf{X}_{\mathbf{c}} \\
{[\%]}\end{array}$ & $\begin{array}{c}\text { Strength } \\
{[\mathrm{MPa}]}\end{array}$ & $\begin{array}{c}\text { Modulus } \\
\text { [MPa] }\end{array}$ \\
\hline$S 1^{\mathrm{a}}$ & $100 / 0 / 0 / 0$ & 163.1 & 81.8 & 108.7 & 91.0 & 39.15 & $32.83(1.1)^{\mathrm{b}}$ & $441.7(21.3)^{\mathrm{c}}$ \\
\hline $\mathrm{S} 2^{\mathrm{a}}$ & $100 / 1 / 3 / 0$ & 165.9 & 90.4 & 111.9 & 92.0 & 42.24 & $36.95(7.1)$ & $584.7(27.2)$ \\
\hline $\mathrm{S} 3^{\mathrm{b}}$ & $100 / 1 / 3 / 10$ & 164.8 & 88.3 & 113.6 & 86.8 & 43.25 & $37.83(1.4)$ & $750.3(45.4)$ \\
\hline $\mathrm{S} 4^{\mathrm{b}}$ & $100 / 1 / 3 / 20$ & 165.4 & 79.0 & 117.8 & 82.6 & 37.82 & $38.22(1.9)$ & $830.1(51.0)$ \\
\hline $\mathrm{S} 5^{\mathrm{b}}$ & $100 / 1 / 3 / 30$ & 165.2 & 78.7 & 118.3 & 78.2 & 37.63 & $40.08(9.5)$ & $905.6(54.9)$ \\
\hline S6 $6^{a}$ & $100 / 3 / 6 / 0$ & 166.2 & 87.5 & 110.8 & 88.2 & 42.20 & $38.02(1.2)$ & $634.9(34.0)$ \\
\hline $\mathrm{S} 7 \mathrm{~b}$ & $100 / 3 / 6 / 10$ & 164.7 & 75.7 & 117.8 & 80.9 & 41.85 & $36.55(1.9)$ & $782.0(19.5)$ \\
\hline $\mathrm{S} 8^{\mathrm{b}}$ & $100 / 3 / 6 / 20$ & 165.5 & 69.7 & 117.0 & 72.4 & 33.36 & $37.34(0.8)$ & $836.4(36.1)$ \\
\hline S9b & $100 / 3 / 6 / 30$ & 164.6 & 67.6 & 118.6 & 70.0 & 32.35 & $36.46(1.8)$ & $958.4(26.6)$ \\
\hline $\mathrm{S} 10^{\mathrm{a}}$ & $100 / 5 / 10 / 0$ & 165.5 & 89.1 & 111.4 & 88.8 & 42.65 & $41.16(1.0)$ & $755.5(34.0)$ \\
\hline S11 & $100 / 5 / 10 / 10$ & 165.4 & 79.6 & 115.6 & 82.8 & 38.09 & $47.63(1.4)$ & $871.3(31.2)$ \\
\hline $\mathrm{S} 12^{\mathrm{b}}$ & $100 / 5 / 10 / 20$ & 166.1 & 72.2 & 116.4 & 76.8 & 34.53 & $38.51(1.5)$ & $867.4(46.4)$ \\
\hline S13 & 100/5/10/30 & 164.9 & 65.2 & 118.1 & 68.8 & 31.20 & $39.90(1.6)$ & 963.8 (36.9) \\
\hline
\end{tabular}

$\mathrm{a}$ and $\mathrm{b}$ the hybrid systems made using a one-step and two-step compounding method, respectively

${ }^{c}$ mean and standard deviation based on five samples. MAPP $=$ maleated polypropylene, $\mathrm{WF}=$ wood flour

$T_{m}=$ melting point; $\Delta H_{m}=$ enthalpy; $T_{c}=$ crystalline temperature; $-\Delta H_{m}=$ crystalline enthalpy; $X_{c}=$ crystallinity

pared to the hybrids without wood flour. This result indicates that the nucleating effect of clay was further strengthened by the addition of wood flour (Table 1).

The crystalline enthalpy $\left(-\Delta H_{m}\right)$ of neat PP was $90.95 \mathrm{~J} / \mathrm{g}$. As clay, MAPP and wood flour were added, the $-\Delta H_{m}$ decreased (Table 1). Since the addition of clay and wood flour interfered with crystallization, it is assumed that the decrease of $-\Delta H_{m}$ was closely related to the decrease of crystal size itself. However, crystallization occurs because the clay and wood flour played a role of nucleating agent. As shown in Table 1, the crystallinity $\left(X_{c}\right)$ of PP was $39.15 \%$. With the addition of clay and MAPP into neat PP, the $X_{c}$ increased. As clay loading increased, the $X_{c}$ of hybrids decreased gradually. The addition of wood flour (10 phr) had no significant effect on the $X_{c}$, while the higher loading of wood flour (20-30 phr) greatly reduced the $X_{c}$. This indicates that the $X_{c}$ is generally affected by the dispersion, the loading level, the surface chemistry of fillers and the viscosity of hybrids [31].

\subsection{Mechanical properties}

The tensile properties of wood flour/clay hybrids manufactured by the one-step and two-step compounding methods are summarized in Table 1 . The tensile strength and modulus of neat PP (S1) were, respectively, 32.8 and $441.7 \mathrm{MPa}$. Figure $3 \mathrm{a}$ shows
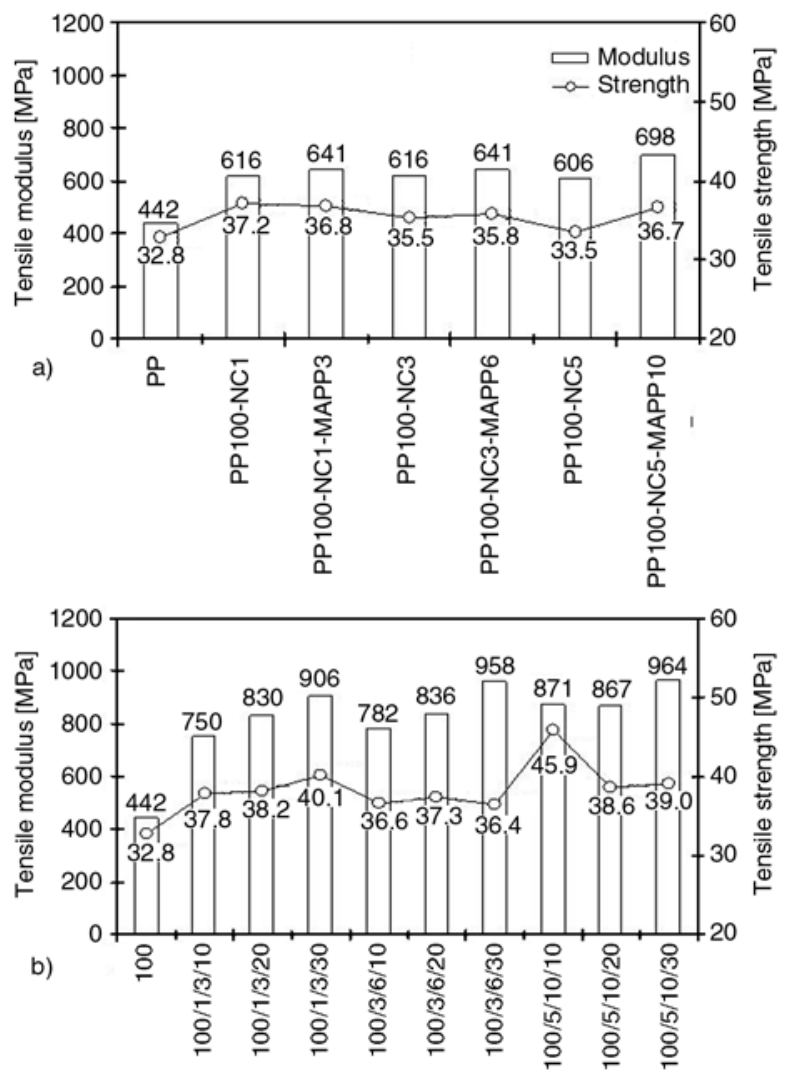

Figure 3. Tensile properties of (a) PP/clay/MAPP hybrids; (b) PP/clay/MAPP/wood flour hybrids

the effect of clay and compatibilizer contents on the tensile properties of hybrids made by the one-step compounding method. The addition of clay $(1,3$ and $5 \mathrm{phr}$ ) to PP increased the tensile modulus to 37.1 to $39.4 \%$ and increased the tensile strength to 
9.1 to $13.4 \%$, compared with those of neat PP. However, the loading level of clay to neat PP showed no effect on the tensile modulus of hybrids. The addition of clay (1, 3 and $5 \mathrm{phr})$ and MAPP (3, 6 and10 phr) for systems S2, S6 and S10 increased the tensile modulus and strength, compared with the hybrids with only clay. For example, the tensile modulus of the hybrid with $5 \mathrm{phr}$ clay and $10 \mathrm{phr}$ MAPP increased by $15.2 \%$ and the tensile strength increased by $9.6 \%$, compared with the hybrids without MAPP. From these results, the high tensile strength is seen to be an intercalation phenomenon of clay layers by MAPP. On the other hand, the increased tensile modulus is attributed to the increased stiffness and brittleness of hybrid composites by the addition of clay.

Figure $3 \mathrm{~b}$ shows the influence of clay, compatibilizer and wood flour contents on the tensile modulus of the hybrids made by the two-step compounding method. At the loading level of $1 \%$ clay, the tensile modulus of hybrids increased as wood flour content increased. As wood flour loading increased to 10,20 and $30 \mathrm{phr}$, the tensile modulus increased $21.8,34.7$ and $47.1 \%$, respectively, compared to the system S2. The tensile modulus of most hybrids was highly increased with the increased loading of clay, MAPP and wood flour, compared to the hybrids (S2, S6 and S10). The maximum tensile modulus (964 MPa) was obtained from system S13. This value is $38.1 \%$ higher than that of system $\mathrm{S} 10$. From these results, it is assumed that the increased modulus is highly related to the increased brittleness and stiffness of the hybrids, due to the addition of wood flour.

The influence of clay, compatibilizer and wood flour contents on the tensile strength of the hybrids is shown in Figure 3b. At the loading of 1 phr clay, the tensile strength of hybrids increased as wood flour content increased. As wood flour loading increased to 10, 20 and $30 \mathrm{phr}$, the tensile strength increased 2.7, 3.8 and $9.0 \%$, respectively, compared to system S2. On the other hand, the tensile strengths of hybrids at a clay loading level of $3 \mathrm{phr}$ were lower than those at $1 \mathrm{phr}$ clay. At $3 \mathrm{phr}$ clay, the tensile strengths of the clay/MAPP hybrid composites with 10, 20 and $30 \mathrm{phr}$ wood flour were increased by $2.2,4.2$ and $1.7 \%$, respectively, compared to system S6. In other words, the tensile strengths leveled-off as the wood flour loading increased. At $5 \mathrm{phr}$ clay loading, the tensile strength of hybrids decreased as wood flour content increased. The maximum tensile strength (45.9 MPa) was obtained at the wood flour loading of $10 \mathrm{phr}$ (system S11). The tensile strengths of clay/MAPP hybrid composites with 20 and $30 \mathrm{phr}$ wood flour were increased by 5.2 and $6.3 \%$, compared to those of system S10. These results indicate that the increase in tensile strength with the increase of wood flour at low levels of clay is related to the improved bonding strength between wood flour and neat PP compared to the intermolecular bonding of neat PP $[2,8]$. It is assumed that the decrease in tensile strength with increasing wood flour at higher clay levels is highly related to the increased viscosity of the hybrids rather than the boding strength.

\subsection{Morphology from WAXD and TEM}

\subsubsection{WAXD results}

The WAXD of clay reinforced PP composites can quantify the periodic intercalated structures of inorganic crystalline layers in the $2 \theta$ range of 2 to $10^{\circ}$ Therefore, the clay product with a d-spacing of $30.3 \AA(2 \theta=2.91)$, was compared with hybrid composites. Figure $4 \mathrm{a}$ and Table 2 illustrate the
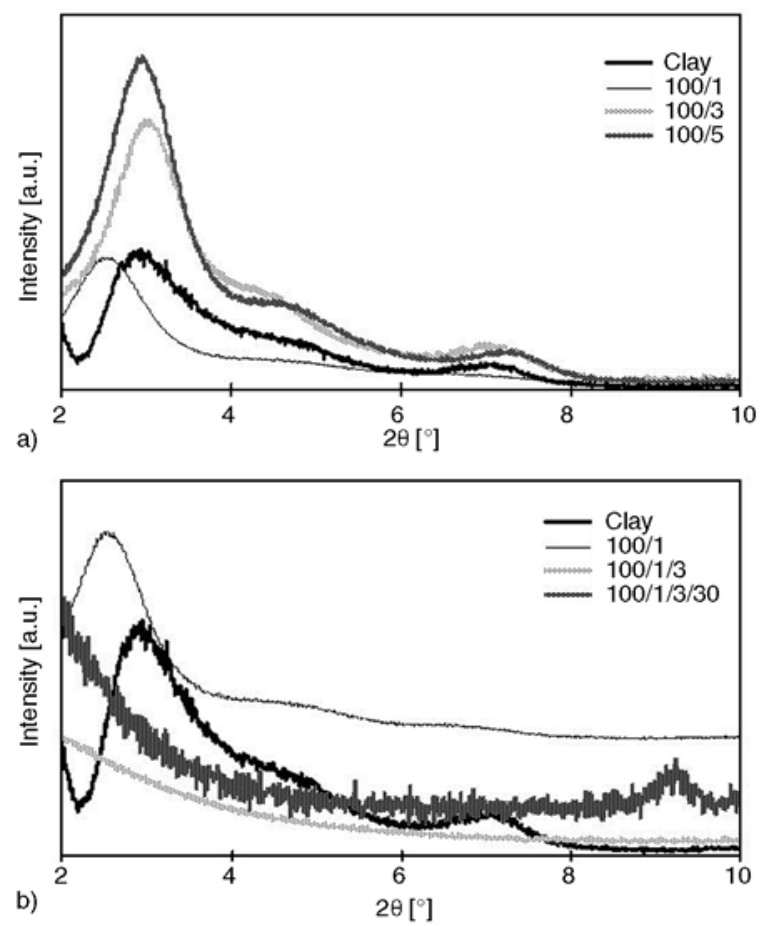

Figure 4. WAXD patterns of selected composite systems (a) clay and PP/clay hybrids; (b) clay, PP/clay, $\mathrm{PP} /$ clay/MAPP, and PP/clay/MAPP/wood flour hybrids 
Table 2. Interlayer distance of clay by wide angle X-ray diffraction

\begin{tabular}{|c|c|c|c|}
\hline Systems & PP/clay & Value at $2 \theta\left[{ }^{\circ}\right]$ & do01 $_{0}$ spacing $[\AA]$ \\
\hline $\mathrm{S} 1^{\mathrm{a}}$ & $100 / 0$ & 2.91 & 30.3 \\
\hline$S 2^{\mathrm{a}}$ & 100/1 & 2.59 & 34.1 \\
\hline $\mathrm{S}^{\mathrm{a}}$ & $100 / 2$ & 2.95 & 29.9 \\
\hline $\mathrm{S} 4^{\mathrm{a}}$ & $100 / 3$ & 3.10 & 28.5 \\
\hline $\mathrm{S}^{\mathrm{a}}$ & $100 / 4$ & 3.05 & 29.0 \\
\hline $56^{a}$ & $100 / 5$ & 3.00 & 29.4 \\
\hline
\end{tabular}

ahybrid systems made using a one-step compounding method

comparison of WAXD patterns of hybrid composites with different levels of clay. The (001) peak of the hybrid with $1 \mathrm{phr}$ clay was shifted to a lower value $(2 \theta=2.95$, d-spacing $=34.1 \AA)$, which indicates an increase of $d$-spacing for clay layers. On the other hand, the (001) peaks of hybrids with 2 to 5 phr clay were shifted to a higher value (minimum $2 \theta=3.10$, d-spacing $=28.5 \AA$ ), which indicates a decrease in d-spacing for clay layers. This decrease of the d-spacing of clay layers is presumably due to the low compatibility at interfaces between neat PP and clay.

Through the enhancement of the compatibility between neat PP and clay, the polymer chains could be well diffused into the clay layers and the d-spacing of clay layers might be increased (Figure 4b). Therefore, the peaks disappeared when $3 \mathrm{phr}$ MAPP was incorporated, representing the intercalation of PP into the clay layers or the partial exfoliation of the clay layers. The (001) peaks of WAXD of the composites with the MAPP showed a broad and weak peak intensity compared to the (001) peaks of WAXD without MAPP. The (001) peaks of WAXD with wood flour/MAPP/clay hybrid prepared by the two-step compounding method are shown in Figure $4 \mathrm{~b}$. The addition of wood flour with clay and MAPP gave much wider peaks, indicating the improved compatibility of wood flour and PP matrix by adding MAPP and the enhancement of intercalation from the better shear action by adding wood flour during the compounding process.

\subsubsection{TEM results}

The TEM photomicrographs of the hybrids with clay, MAPP and wood flour prepared by the onestep and two-step compounding are shown in Figures $5 \mathrm{a}-5 \mathrm{~h}$. The dark lines in Figures $5 \mathrm{a}$ and $5 \mathrm{~b}$ correspond to the intersection of clay layers of $3.15 \mathrm{~nm}$ thick clay layers, showing a large number of multi-layered stacks of clay platelets, and no clay platelets intercalated with polymer. The TEM photomicrographs in Figures $5 \mathrm{c}$ and $5 \mathrm{~d}$ contain a large number of multilayered clay platelets intercalated with PP, corroborating the WAXD results [15]. This result is closely related to the enhancement of clay dispersion by MAPP and the intercalation of clay platelets with polymer. Moreover, the TEM photomicrographs in Figures $5 \mathrm{e}-5 \mathrm{~h}$ reveal well-intercalated and partially exfoliated structures containing dispersed layers of clay, showing a larger number of platelets per unit area on average. With the addition of wood flour, the intercalated and partially exfoliated structures were clearly detected.

\section{Conclusions}

The effects of clay, wood flour and compatibilizer on the melting and crystallization behavior, mechanical properties and morphology of PP/clay/ wood flour nanocomposites were studied. The addition of clay ( 1 to $5 \mathrm{phr}$ ), compatibilizer (5 to $10 \mathrm{phr}$ ) and wood flour (10 to $20 \mathrm{phr}$ ) increased the decomposition temperature and melting temperature of the hybrids. The crystalline peak temperature of the hybrids increased with the use of clay and wood flour compared to that of neat PP. The crystalline enthalpy largely decreased due to the increase of viscosity and the decrease of dispersion in the polymer as clay, compatibilizer and wood flour were added. The addition of clay to neat PP increased the tensile modulus and strength. The addition of clay and MAPP to neat PP increased the tensile modulus and strength, compared with the hybrids with only clay. The tensile modulus and strength of most hybrids were highly increased with the increased loading of clay, MAPP and wood flour, compared to the hybrids without wood flour. The increased tensile modulus is attributed to the increased stiffness and brittleness of hybrid composites by the addition of clay and wood flour. On the other hand, the high tensile strength is related to an intercalation phenomenon of clay layers and the increased bonding strength between wood flour and neat PP by MAPP. The WAXD pattern of the hybrids showed increased d-spacing of clay layers, indicating improved compatibility of 

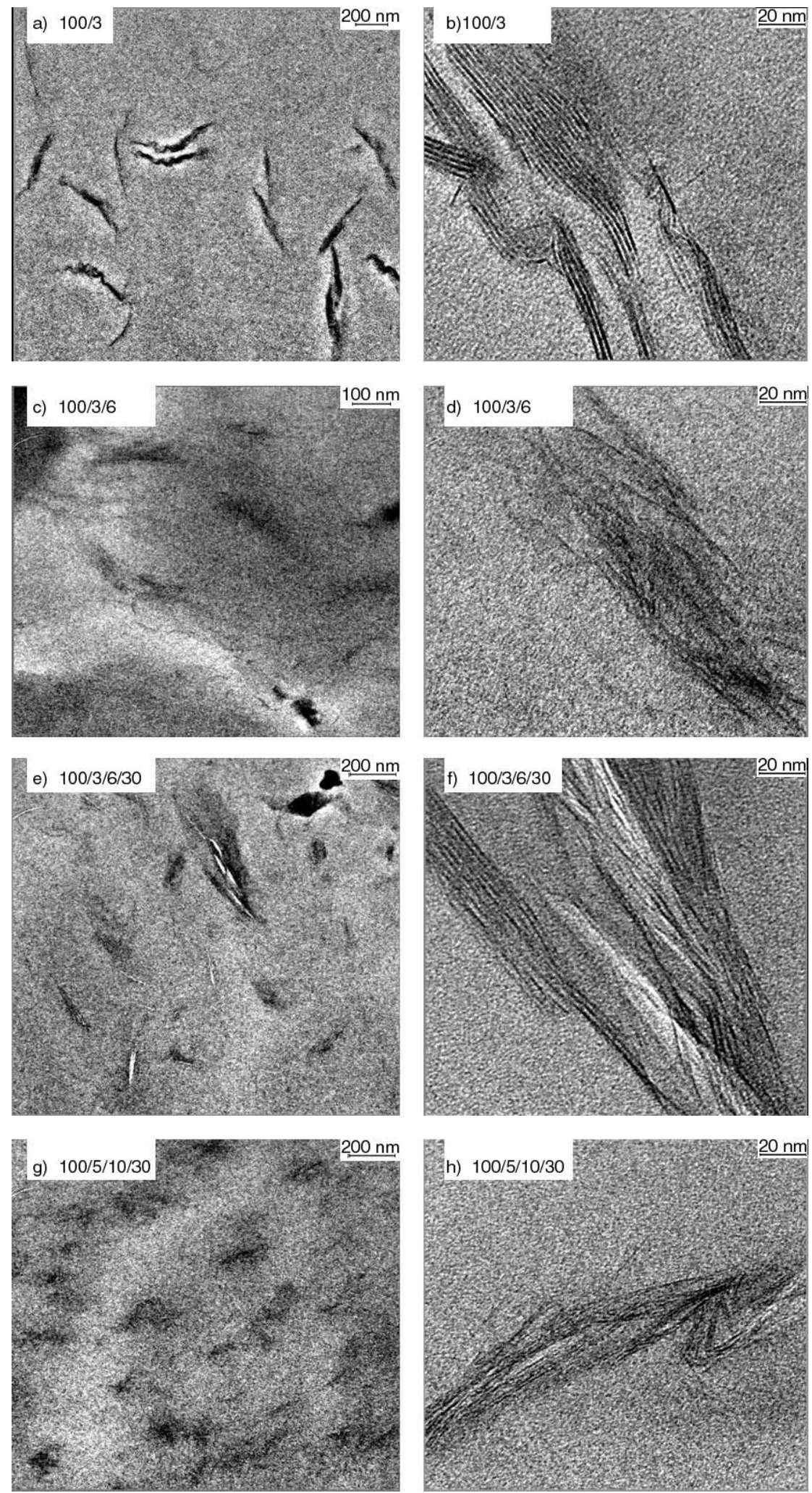

Figure 5. TEM images of PP/clay/MAPP/wood flour hybrids. a) and b) PP/clay: 100/3; c) and d) PP/clay/MAPP: 100/3/6; e) and f) PP/clay/MAPP/WF: 100/3/6/30; and g) and h) PP/clay/MAPP/WF: 100/5/10/30. Scale-bar of (a), (c), (e), and (g) was $100 \mathrm{~nm}$, and scale-bar of (b), (d), (f), (h) was $20 \mathrm{~nm}$

neat PP and clay by the addition of MAPP and the intercalation and partial exfoliation of clay layers. The TEM photomicrographs further illustrated the intercalated and partially exfoliated structures formed by the addition of clay, MAPP and wood flour. From this study, the desired composite properties can be tailored by a synergetic combination 
of clay and coupling agent with the presence of large-size wood flour.

\section{References}

[1] Bledzki A. K., Gassan J.: Composites reinforced with cellulose fibres. Progress in Polymer Science, 24, 221-274 (1999).

[2] Lee S-Y., Yang H-S., Kim H-J., Jeong C-S., Lim B-S., Lee J-N.: Creep behavior and manufacturing parameters of wood flour filled polypropulene composites. Composite Structures, 65, 459-469 (2004).

[3] Kim H-S., Yang H-S., Kim H-J., Park H-J.: Thermogravimetric analysis of rice husk flour filled thermoplastic polymer composites. Journal of Thermal Analysis and Calorimetry, 76, 395-404 (2004).

[4] Svelto C., Taccheo S., Bava E., Laporta P., Joseph P. V., Joseph K., Thomas S.: Effect of processing variables on the mechanical properties of sisal-fiber-reinforced polypropylene composites. Composite Science and Technology, 59, 1625-1640 (1999).

[5] Rana A. K., Mandal A., Mitra B. C., Jacobson R., Rowell R., Banerjee A. N.: Short jute-reinforced polypropylene composites: Effect of compatibilizer. Journal of Applied Polymer Science, 69, 329-338 (1998).

[6] Premalal B. H. G., Ismail H., Baharin A.: A comparison of the mechanical properties of rice husk powder filled polypropylene composites with talc filled polypropylene composites. Polymer Testing, 21, 833839 (2002).

[7] Yang H-S., Kim H-J., Son J., Park H-J. Lee B-J., Hwang T-S.: Rice husk flour filled polypropylene composites: mechanical and morphological study. Composite Structures, 63, 305-312 (2004).

[8] Lu J. Z., Wu Q., McNabb Jr. H. S.: Chemical coupling in wood fiber and polymer composites: A review of coupling agents and treatments. Wood Fiber Science, 32, 88-104 (2000).

[9] Woodhams R. T., Thomas G., Rodgers D. K.: Wood fibers as reinforcing fillers for polyolefins. Polymer Engineering and Science, 24, 1166-1171 (1984).

[10] Clemons C.: Wood-plastic composites in the United States: The interfacing of two industries. Forest Products Journal, 52, 10-18 (2002).

[11] Oksman K., Sain M.: Cellulose nanocomposites: processing, characterization and properties. ACS Symposium Series, Washington D.C. (2005).

[12] Pinnavaia T. J., Beall G. W.: Polymer-clay nanocomposites. John Wiley and Sons, West Sussex (2000).

[13] Ajayan P. M., Schadler L. S., Braun P. V.: Nanocomposite Science and Technology. Wiley-VCH, Weinheim (2006).

[14] Ktawczak P.: Compounding and processing of polymer nanocomposites: from scientific challenges to industrial stakes. Express Polymer Letters, 1, 188 (2007).
[15] Giannelis E. P., Krishnaoorti R., Manias E.: Polymersilicate nanocomposites: model system for confined polymers and polymer brushes. Advances in Polymer Science, 138, 107-147 (1999).

[16] Kojima Y., Usuki A., Kawasumi M., Okada A., Fukushima Y., Kurauchi T., Kamigaito O.: Mechanical properties if nylon 6-clay hybrid. Journal of Material Research, 8, 1185-1189 (1993).

[17] Liu T. X., Liu Z. H., Ma K. X., Shen L., Zeng K. Y., He C. B.: Morphology, thermal and mechanical behavior of polyamide 6/layered-silicate nanocomposites. Composite Science and Technology, 63, 331-337 (2003).

[18] Lee S. U., Oh I. H., Lee J. H., Choi K. Y., Lee S. G.: Preparation and characterization of polyethylene/ montmorillonite nanocomposites. Polymer (Korea), 3, 271-276 (2005).

[19] Lee S. G., Won J. C., Lee J. H., Choi K-Y.: Flame retardancy of polyproplynene-Montmorillonite nanocomposites. Polymer (Korea), 29, 248-252 (2005).

[20] Chow W. S.: Water absorption of epoxy/glass fiber/ organo-montmorillonite nanocomposites. Express Polymer Letters, 1, 104-108 (2007).

[21] Lei Y., Wu Q., Clemons C. M.: Preparation and properties of recycled HDPE/clay Hybrids. Journal of Applied Polymer Science, 103, 3056-3063 (2006).

[22] Fornes, T. D., Yoon P. J., Hunter D. L., Keskkula H., Paul D. R.: Effect of organoclay structure on nylon 6 nanocomposites morphology and properties. Polymer, 43, 5915-5933 (2002).

[23] Wu Q., Liu X., Berglund L. A.: FT-IR spectroscopic study of hydrogen bonding in PA6/clay nanocomposites. Polymer, 43, 2445-2449 (2002).

[24] Yoon P. J., Fornes T. D., Paul D. R.: Thermal expansion behavior of nylon 6 nanocomposites. Polymer, 43, 6727-6741 (2002).

[25] Carrado K. A., Xu L., Seifert S., Csencsits R., Bloomquist C. A.: Polymer-clay nanocomposites derived from polymer-silicate gels. in 'Polymer-Clay Nanocomposites' (Eds.: by Pinnavaia T. J. and Beall G. W.) John Wiley and Sons, Chichester 47-63 (2001).

[26] Qin H., Zhang S., Zhao C., Feng M., Yang M., Shu Z., Yang S.: Thermal stability and flammability of polypropylene/montmorillonite composites. Polymer Degradation and Stability, 85, 807-813 (2004).

[27] Zanetti M., Camino G., Peichert P., Mülhaupt R.: Thermal behavior of poly(propylene) layered silicate nanocomposites. Macromolecular Rapid Communcations, 22, 176-180 (2001).

[28] Lee S. Y., Doh G. H., Kang I. A.: Thermal behavior of hwangto and wood flour reinforced high density polyethylene (HDPE) composites. Mokchae Konghak, 34, 59-66 (2006). 
[29] Liang G., Xu J., Bao S., Xu W.: Polyethylene/maleic anhydride grafted polyethylene/organic-montmorillonite nanocomposites. Preparation, microstructure, and mechanical properties. Journal of Applied Polymer Science, 91, 3974-3980 (2004).

[30] Gopakumar T. G., Lee J. A., Kontopoulou M., Parent J. S.: Influence of clay exfoliation on the physical properties of montmorillonite/polyethylene composites. Polymer, 43, 5483-5491 (2002).
[31] Wang K. H., Choi M. H., Koo C. M., Xu M., Chung I. J., Jang M. C., Choi S. W., Song H. H.: Morphology and physical properties of polyethylene/silicate nanocomposite prepared by intercalation. Journal of Polymer Science, Part B: Polymer Physics, 40, 1454 1463 (2002). 